\title{
ИССЛЕДОВАНИЕ СУБЪЕКТОВ ИНВЕСТИЦИОННО-СТРОИТЕЛЬНОГО КОМПЛЕКСА НА СОВРЕМЕННОМ ЭТАПЕ
}

\author{
(C) 2018 Беляева Елена Юрьевна \\ аспирант кафедры экономики и управления предприятиями и производственными комплексами \\ Санкт-Петербургский государственный экономический университет \\ 191023, г. Санкт-Петербург, ул. Садовая, д. 21 \\ E-mail: lenaprokopenkova@mail.ru
}

Инвестиционно-строительный комплекс (ИСК) является системой, подверженной влиянию инноваций не только технологического, но и организационного, маркетингового, процессного характера. Вопрос о субъектах инвестиционно-строительного комплекса является актуальным, поскольку именно участники ИСК принимают решения, которые воздействуют на работу комплекса изнутри и, таким образом, являются одной из движущих сил, изменяющих отрасль. Кроме этого, человеческий капитал и организационная эффективность комплекса являются фундаментом перехода к экономике знаний в строительной сфере. В условиях новой экономики на плечи участников инвестиционно-строительного комплекса также ложится роль определения будущего, а именно реализация инновационных целей и задач [28]. В результате исследования дополнена актуальная база субъектов комплекса за счёт подробного научно-теоретического, статистического и законоведческого исследования. Впервые рассмотрены субъекты ИСК на стыке юридического и статистического подходов. Отмечена положительная динамика в законотворческой сфере касательно инвестиционно-строительной отрасли. Выявлена институциональная организационная инновация (консультант), направленная на повышение эффективности работы комплекса.

Ключевые слова: субъекты инвестиционно-строительного комплекса, трудовые ресурсы, инновации, строительство, консультант.

\section{Введение}

Важная роль инвестиционно-строительной среде выделяется не только технологическим аспектам, но и факторам человеческого капитала. Именно человеческий труд различного уровня сложности при качественном взаимодействии групп людей приносит прибыль организациям, комплексам, экономике в целом. В условиях перехода к информационной экономике знаний роль человеческого управления и организации деятельности становится особенно актуальной: необходимо более быстрое реагирование на изменения; квалифицированная оценка возможности внедрения эффективной инновационной составляющей за счёт исследования рынка, наработанного опыта, технико-экономической оценки внедрения инновации, её контроля на всех этапах инвестиционно-строительного цикла при соблюдении определённых временных сроков и ограниченных ресурсов.

Исследованием участников ИСК занимались учёные Асаул А.Н. [19], Донцова Л.В. [22], Вахмистров А.И. [21], Казаков Ю.Н. [24], Иванов С.Н. [23] и др. Инновациям в строительстве посвящены труды Алексеева А.А [18], Асаула А.Н., За- варина Д.А. и др. [20], Федосеева И.В. [30] и др. Вопрос важности трудовых и интеллектуальных ресурсов раскрывается в работах Армстронга М. [32], Капелюшникова Р.И. [25], Карлика А.Е., Платонова В.В. и др. [26].

Актуализация действующих субъектов ИСК позволит организовать эффективные управленческие структуры, за счёт чего наметится возможный путь решения проблемы недостаточной развитости инноваций в комплексе, а также повысится эффективность работы инвестиционно-строительного комплекса. Для понимания закономерностей инновационного и промышленного развития критически важен анализ внутренних факторов [27], таким образом, автору видится целесообразным раскрыть трудовые ресурсы строительной индустрии.

\section{Основная часть}

Со стороны показателя трудовых ресурсов отмечается отрицательная динамика количества работников, задействованных в строительной отрасли. Также наблюдается ещё один существенный недостаток: низкий уровень квалификации сотрудников, причём как со стороны 
рабочей силы, так и со стороны управленческих позиций. Отмеченные отрицательные тенденции автор предлагает решить с помощью организации человеческих ресурсов. С этой целью в работе будет проведён академический анализ, который позволит выделить субъекты и институты, осуществляющие деятельность в инвестиционно-строительном комплексе и определить их отношения с точки зрения институционального подхода. Автором будут проанализированы нормативно-правовые акты, данные статистического учёта, а также авторитетные научные источники. Таким образом, анализ будет проводиться с помощью трёх подходов: законоведческого, статистического и научно-теоретического.

Для академического исследования и выделения субъектов и институтов, осуществляющих деятельность в инвестиционно-строительном комплексе и определения их отношений с точки зрения институционального подхода, автор предлагает проанализировать нормативно-правовые акты, данные статистического учёта, а также авторитетные научные источники. Таким образом, анализ будет проводиться с помощью трёх подходов: законоведческого, статистического и научно-теоретического.

1. Законоведческий подход

За период 2013-2018 гг. органами государственной власти была проведена основательная работа по изменению и дополнению существующих документов, регламентирующих инвестиционно-строительную деятельность. Автором были выделены наиболее значимые нормативно-правовые акты, которые касаются отрасли строительства [1-17].

На основании данных документов автором были выделены субъекты инвестиционно-строительного комплекса, представленные в табл. 1.

Данная таблица довольно полно отражает участников инвестиционно-строительной сферы. Автор провел сравнительный анализ нормативной документации и пришёл к следующим выводам.

Наиболее значимыми участниками, как правило, признаются пользователь, застройщик, заказчик, подрядчик, лицо, выполняющее инженерные изыскания, лицо, осуществляющее подготовку проектной документации, изыскатель, архитектор, проектировщик, инвестор, участники долевого строительства, саморегулируемые организации [19, 21-24].
Однако актуальная законодательная база выделяет также следующих участников ИСК:

- кредитные организации и финансовые организации;

- разработчик;

- агент;

- лица, участвующие в процессе проектирования (включая изыскания), производства, строительства, монтажа, наладки, эксплуатации, хранения, перевозки, реализации, утилизации, захоронения;

- арендатор объекта недвижимости;

- помощники, консультанты и технические работники;

- религиозная организация;

- организации коммунального комплекса;

- орган архитектуры и градостроительства;

- органы государственной власти РФ, органы государственной власти субъектов РФ, органы местного самоуправления;

- потребители;

- собственники, арендаторы, правообладатели земельных участков;

- иные субъекты предпринимательской или профессиональной деятельности.

Безусловной и всё ещё нерешенной проблемой является отсутствие чётких границ терминов и определений. Большинство законодательных актов фигурируют понятиями «и другие», «и иные» субъекты профессиональной, строительной, инвестиционной деятельности. Таким образом, единый подход к определению хозяйственных взаимоотношений между субъектами инвестиционно-строительного комплекса отсутствует. Из-за этой проблемы чаще всего страдают конечные пользователи объектов недвижимости. Проблема дефиниций существенна, становление инвестиционно-строительного комплекса как единой системы в научном и практическом аспекте опережает описание взаимодействий и взаимоотношений в законодательстве. Частично эту проблему можно объяснить контрактным взаимодействием участников комплекса, что дает, с одной стороны, большую свободу для субъектов, занятых в инвестиционно-строительной сфере, с другой стороны - сложности при возникновении проблем при отсутствии подробного описания или не описания механизма решения вопроса в контракте.

Однако нельзя не отметить положительную динамику в законотворческой сфере - учтены 


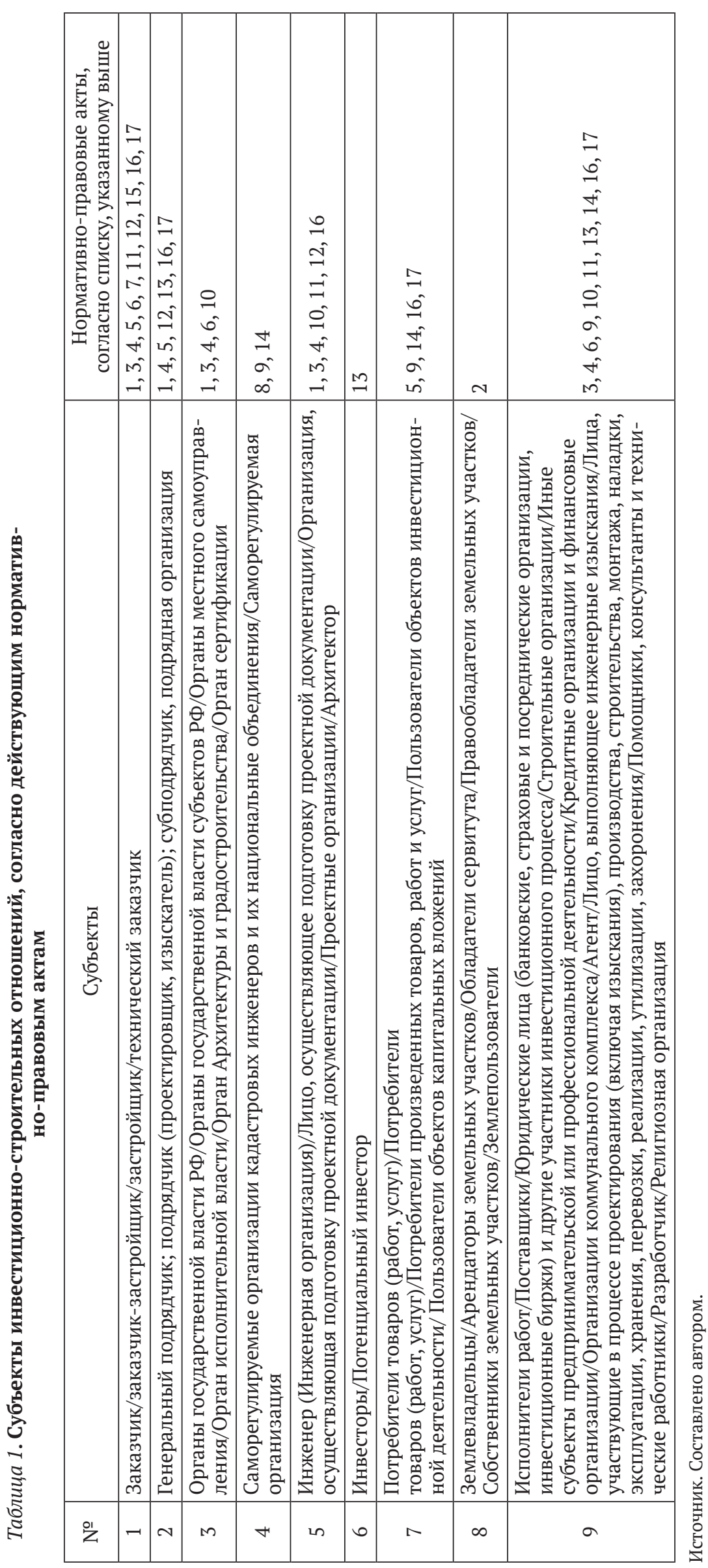


фактически все участники инвестиционно-строительной деятельности, за исключением девелопера. Данный субъект играет важную роль при строительстве и освоении территорий новых районов. Зачастую данная функция включена в контракт застройщика.

Неоинституционализм позволяет провести исследование по группировке субъектов комплекса в рамках как формального (количественные значения), так и неформального воздействия на субъекты отношений в инвестиционно-строительной сфере. Автору затруднительно выделить выручку согласно новой структуре Общероссийского классификатора видов экономической деятельности (ОКВЭД(2)) из-за отсутствия данных статистики, однако проведение анализа на стыке законоведческого и статистического подхода является возможным и целесообразным.

Таким образом, автором была составлена таблица и проведён анализ субъектов инвестиционно-строительного комплекса в рамках системы ОКВЭД (2) и законодательных актов.

Система статистической классификации ОКВЭД(2) - это инструмент, с помощью которого сегодня возможно описать как строительную отрасль, так и взаимодействующие с ней области, поскольку, согласно ОКВЭД(2): «если данная деятельность осуществляется для эксплуатации построенных объектов, то все виды работ относятся к строительству» [29].

Инвестиционно-строительный комплекс выделяется не только через вид деятельности $\mathrm{F}$ (строительство), но также и через другие виды деятельности, такие как добыча полезных ископаемых (B), обрабатывающие производства $(\mathrm{C})$, обеспечение электрической энергией, газом и паром; кондиционирование воздуха (D), водоснабжение; водоотведение, организация сбора и утилизации отходов, деятельность по ликвидации загрязнений (Е), строительство (F), транспортировка и хранение $(\mathrm{H})$, деятельность в области информации и связи (J), деятельность финансовая и страховая (К), деятельность по операциям с недвижимым имуществом (L), деятельность профессиональная, научная и техническая (M).

Автор на основании проведённого анализа также выделяет нового субъекта деятельности, чей институт только зарождается в инвестиционно-строительном комплексе России - консультанта. Деятельность по оказанию консуль- тационных услуг, согласно ОКВЭД(2), связана в большей степени с проектированием и архитектурными разработками. Однако для инвестиционно-строительного комплекса формирование данного института имеет большое значение с трансформационной точки зрения - появление такого субъекта деятельности, как консультант, является организационной инновацией в ИСК.

Рынок консалтинговых услуг в России, по мнению экспертов, пока пребывает в стагнации. В ближайшее время переход к росту может осуществиться за счёт спроса со стороны заказчиков из АПК, промышленного и жилищного строительства, которых обращаться к техническим аудиторам и консультантам стимулирует законодательство» [33]. Крупными компаниями в сфере строительного консалтинга являются «Knight Frank» «Интертрест», «Олса», «СМАРТ-И», «2К», «Беркшир технолоджи», «Центр независимой экспертизы собственности» и др. [34] Они осуществляют свою деятельность по различным направлениям в сфере строительства, включая помощь в стратегическом планировании проекта, развитии инвестиционных проектов, технических аспектах, проектировании и дизайне, экологическом строительстве, юридической поддержке на рынке недвижимости и других видах консультационных услуг.

В целом оборот консалтинговых компаний, которые предоставили отчетную информацию в отношении строительного комплекса за период 2015-2016 гг. составил немалую сумму, и был равен, соответственно, 653, 9 млн. руб. 1132 млн. руб. [34].

На базе университета СПбГЭУ автором совместно с научным руководителем Алексеевым А.А. был проведён экспертный опрос среди консалтинговых строительных компаний, в результате которого выяснилось, что услуги консультантов в инвестиционно-строительном комплексе России являются востребованным и перспективным направлением, так как 70\% компаний считают, что услуги строительного консалтинга востребованы (7 из 10 опрошенных фирм), 20\% - очень востребованы, 10\% - не востребованы.

На рисунке 2 автор схематично отобразил организационную структуру, которая отражает организационную инновацию - консультанта проекта в ИСК. Видно, что из архаичной формы взаимодействия «заказчик-подрядчик» возможно перерождение в форму «консультант-заказ- 


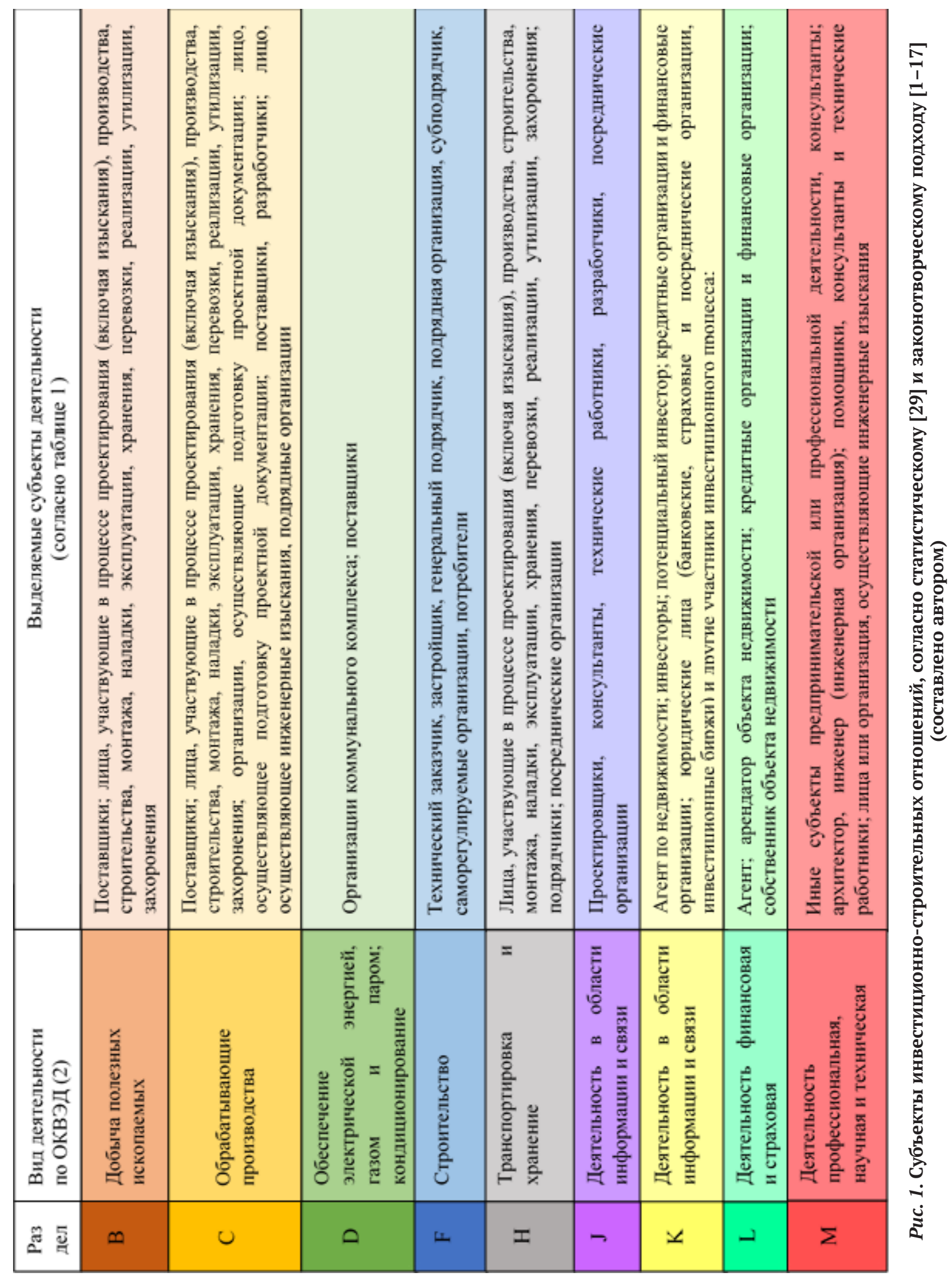




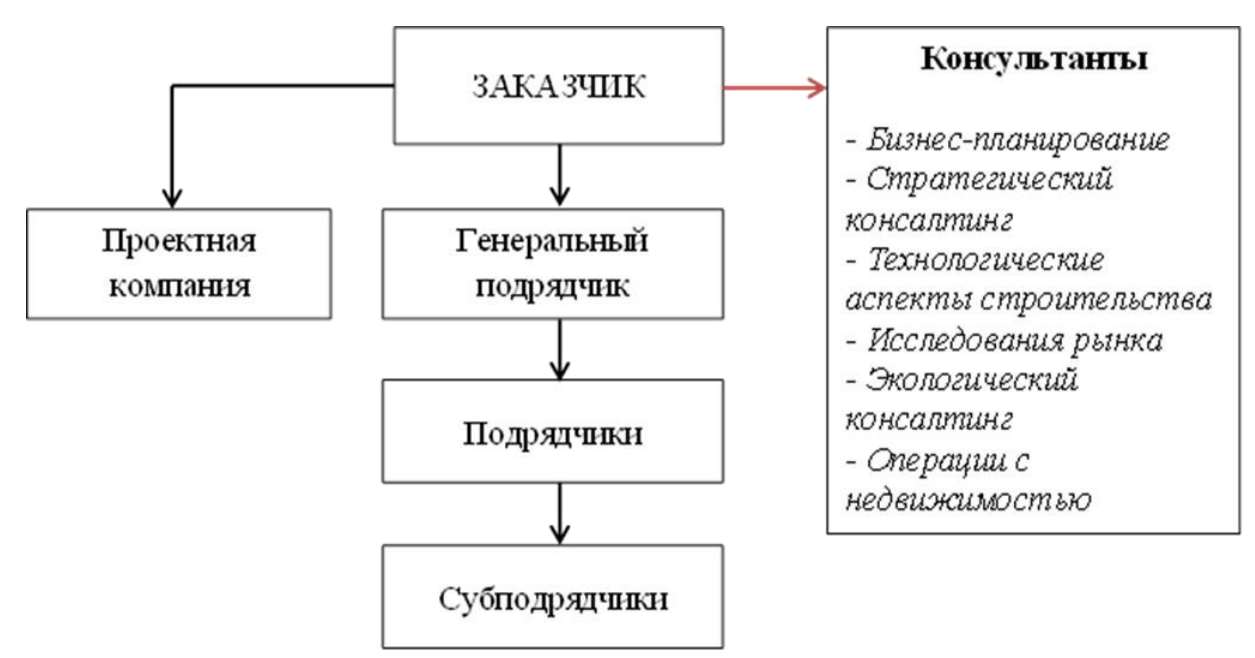

Puc. 2. Схема применения консультантов по различным направлениям деятельности в ИСК как организационная инновация

чик-подрядчик».

Предложенная автором схема позволяет оптимизировать деятельность субъектов ИСК в условиях ограниченных трудовых ресурсов и недостаточной квалификации за счёт внедрения консультантов и интеграции их знаний в инвестиционно-строительную сферу.

Данные нематериальные услуги (консультации, советы) помогают принимать решения на любой проектной стадии, при этом осведомленность специалистов-консультантов позволяет не только решать текущие задачи, но и внедрять инновационные продукты, материалы, технологии в строительный цикл, тем самым обеспечивая развитие ИСК с точки зрения продуктовых и процессных инноваций. Эти нововведения обеспечивают рост экономической эффективности через снижение накладных расходов, экономию на транзакционных издержках [27], т.е. приносят экономически положительную динамику. Помимо этого, эффективность такой организации была доказана данными журнала Doing Business [32], которые показывают, что вовлечение в строительную индустрию частных третьих лиц (консультантов) связано с лучшим качеством строительства, что было измерено индексом «качество контроля строительства». Фактически 93 из 190 исследованных экономик используют некоторую форму частных услуг третьих лиц в управлении строительством. В высокодоходных экономиках и экономиках с доходами выше среднего 66,1\% и 56,7\%, соответственно, используют услуги консультантов в управлении стро- ительной деятельностью, в то время как только 37,7\% из экономик, чьи доходы ниже среднего, используют услуги третьих лиц, и лишь 25\% низкодоходных экономик используют консультационные услуги в строительной отрасли.

\section{Заключение}

На основании проведённого исследования автор выделил следующие тезисы касательно субъектов инвестиционно-строительного комплекса на современном экономическом этапе:

Во-первых, была отмечена тенденция уменьшения количества участников инвестиционно-строительного комплекса.

Во-вторых, несмотря на нечёткость определений субъектов комплекса, автор отмечает положительную динамику в сфере законодательства - учтены фактически все участники инвестиционно-строительной деятельности, за исключением девелопера.

В-третьих, был выделен новый субъект деятельности - консультант. Перспективность данного направления в строительной сфере доказана мнением экспертов и опросом среди компаний-респондентов, занятых в консалтинге, проведённым автором совместно с научным руководителем.

В четвертых, была предложена организационная инновация в ИСК -услуги консалтинговых фирм, направленная на повышение эффективности работы комплекса за счёт оптимизации деятельности участников ИСК. 


\section{Библиогафический список}

1. Гражданский Кодекс Российской Федерации от 30.11.1994 № 51-ФЗ (ред. от 03.07.2016) (с изм. и доп., вступ. в силу с 01.01.2017).

2. Земельный кодекс Российской Федерации от 25.10.2001 № 136-Ф3.

3. Градостроительный кодекс Российской Федерации от 29.12.2004 № 190-ФЗ (ред. от 03.07.2016) (с изм. и доп., вступ. в силу с 01.09.2016).

4. Федеральный закон от 17.11.95 № 169-ФЗ «Об архитектурной деятельности в Российской Федерации» (ред. от 19.07.2011 № 248-Ф3).

5. Федеральный закон «Об инвестиционной деятельности в Российской Федерации, осуществляемой в форме капитальных вложений» от 25.02.1999 № 39-Ф3 (действующая редакция, 2016).

6. Федеральный закон «О техническом регулировании» от 27.12.2002 № 184-Ф3 (в ред. от 05.04.2016 № 104$\Phi 3)$.

7. Федеральный закон «Об участии в долевом строительстве многоквартирных домов и иных объектов недвижимости и о внесении изменений в некоторые законодательные акты Российской Федерации» от 30.12.2004 № 214-ФЗ (в ред. от 03.07.2016 № 304-ФЗ).

8. Федеральный закон «О государственном кадастре недвижимости» от 24.07.2007 № 221-Ф3 (ред. от 03.07.2016) (с изм. и доп., вступ. в силу с 01.12.2016).

9. Федеральный закон «О саморегулируемых организациях» от 01.12.2007 № 315-Ф3 (ред. от 03.07.2016 № 360-Ф3).

10. Федеральный закон «О содействии развитию жилищного строительства» от 24.07.2008 № 161-ФЗ (ред. от 23.06.2016 № 221-Ф3).

11. Федеральный закон «Технический регламент о безопасности зданий и сооружений» от 30.12.2009 № 384Ф3 (ред. от 02.07.2013).

12. Постановление Правительства РФ от 21.06 .2010 № 468 «О порядке проведения строительного контроля при осуществлении строительства, реконструкции и капитального ремонта объектов капитального строительства»

13. Закон Санкт-Петербурга «О порядке предоставления объектов недвижимости, находящихся в собственности Санкт-Петербурга, для строительства, реконструкции и приспособления для современного использования» от 17.06.2004 № 282-43 (ред. от 22.04.2015) (принят ЗС СПб 26.05.2004).

14. Приказ Ростехнадзора от 24.05.2010 № 411 «Об утверждении формы Свидетельства о допуске к определенному виду или видам работ, которые оказывают влияние на безопасность объектов капитального строительства».

15. Приказ Минрегиона Российской Федерации «Об утверждении Перечня видов работ по инженерным изысканиям, по подготовке проектной документации, по строительству, реконструкции, капитальному ремонту объектов капитального строительства, которые оказывают влияние на безопасность объектов капитального строительства» от 30.12.2009 № 624 (ред. от 14.11.2011).

16. Письмо Минрегиона РФ «Об осуществлении строительного контроля» от 30.04.2010» № 17906-ИП/08.

17. Закон РСФСР «Об инвестиционной деятельности в РСФСР» от 26.06.1991 № 1488-1 (ред. от 19.07.2011).

18. Алексеев А.А. Инновации в строительной индустрии: научная дискуссия и библиография //Экономические науки. 2017. № 10 (155). С. 7-11.

19. Асаул А.Н. Экономика недвижимости (Рекомендовано Министерством образования и науки РФ в качестве учебника для студентов высших учебных заведений, обучающихся по специальности Экономика и управление по отраслям»)/ А.Н. Асаул. Санкт-Петербург. 2007.

20. Асаул А.Н. Современные проблемы инноватики: учебное издание / А.Н. Асаул, Д.А. Заварин, С.Н. Иванов, Е.И. Рыбнов; под ред. заслуженного деятеля науки РФ, д-ра экон. наук, проф. А. Н. Асаула. Санкт-Петербург. 2016. 208 c.

21. Вахмистров А.И. Управление инвестиционно-строительным комплексом мегаполиса. Санкт-Петербург. 2004.

22. Донцова Л.В. Инвестиционно-строительная деятельность: назначение, функции, участники, экономические риски // Менеджмент в России и за рубежом. № 6. 1998.

23. Иванов С. Н. Исследование структуры участников регионального инвестиционно-строительного комплекса // Вестник гражданских инженеров. 2008. № 1(14). С. 74-83.

24. Казаков Ю.Н. Современное состояние инвестиционно-строительного комплекса Санкт-Петербурга, Москва. 2007. 
25. Капелюшников Р.И. Сколько стоит человеческий капитал России?: препринт WP3/2012/06 [Текст] // Нац. исслед. ун-т «Высшая школа экономики. Москва. 2012. 76 с.

26. Управление интеллектуальными ресурсами инновационно-активных предприятий / Карлик А.Е. [и др.]. Санкт-Петербург. 2013. 167 с.

27. Карлик А.Е. Организационно-управленческие инновации: резерв повышения конкурентоспособности Российской промышленности / А.Е. Карлик, В.В. Платонов // Экономическое возрождение России. 2015. № 3 (45). С. 34-44.

28. Лепский В.Е. Становление стратегических субъектов: постановка проблемы // Рефлексивные процессы и управление. 2002. Т. 2, № 1. С. 5-23.

29. «ОК 029-2014 (КДЕС Ред.2). Общероссийский классификатор видов экономической деятельности» (утв. Приказом Росстандарта от 31.01.2014 N14-ст) (ред. от 21.12.2017)

30. Федосеев И.В. Совершенствование управления инновационно-инвестиционной деятельностью строительного предприятия в регионе. Санкт-Петербург. 2008.

31. Армстронг М. Практика управления человеческими ресурсами. 10-е изд. / Пер. с англ. под ред. С.К. Мордовина. Санкт-Петербург. 2012. 848 с.

32. Doing Business 2018 // The World Bank Group.- U., 2018.- p. - 50.

33. Рейтинговое Агентство RAEX «Эксперт РА» [Электронный ресурс].- Режим доступа: https://raexpert.ru/ ratings/tech_audit_consulting/2016/, свободный._-Загл. с экрана.

34. Рейтинговое Агентство RAEX «Эксперт РА» [Электронный ресурс].- Режим доступа: https://raexpert.ru/ rankingtable/consult/2016/tab12, свободный.- Загл. с экрана. 